International Journal of Recent advances in Physics (IJRAP) Vol.3, No.2, May 2014

\title{
ANALYSIS OF REACTIVITY ACCIDENT FOR CONTROL RODS WITHDRAWAL AT THE THERMAL REACTOR
}

\author{
Hend M. Saad ${ }^{1}$, M. Aziz ${ }^{1}$, and H. M.Mansour ${ }^{2}$ \\ ${ }^{1}$ Department of Nuclear Safety Engineering, Nuclear and Radiological Regulatory \\ Authority, Nasr City, Cairo 11762, Egypt \\ ${ }^{2}$ Department of Physics, Faculty of Science, Cairo University, Giza 12613, Egypt
}

\begin{abstract}
In the present work, the point kinetics equations are solved numerically using the stiffness confinement method (SCM). The solution is applied to the kinetics equations in the presence of different types of reactivities, and is compared with other methods. This method is, also used to analyze reactivity accidents in thermal reactor at start-up, and full power conditions for control rods withdrawal. Thermal reactor (HTR-M) is fuelled by uranium-235. This analysis presents the effect of negative temperature feedback, and the positive reactivity of control rods withdrawal. Power, temperature pulse, and reactivity following the reactivity accidents are calculated using programming language (FORTRAN), and (MATLAB) Codes. The results are compared with previous works and satisfactory agreement is found.
\end{abstract}

\section{KEYWORDS}

Point Kinetics Equations, Stiffness Confinement Method, Reactivity accident, Control Rods, Reactivity Coefficient, and Safety Analysis.

\section{INTRODUCTION}

For the nuclear reactor, the start-up and shutdown need different values of the reactivity to be inserted, for the power to increase or decrease. However, the improper reactivity insertion may endanger the reactor. For example, the reactivity accident caused by the excessive inserted reactivity, such as the result of control rod withdrawal, will lead to the power burst and a further damage of the core. Reactivity accident due to inadvertent withdrawal of the control rod is one kind of the design basis accident for high temperature gas-cooled reactors, which should be analyzed carefully in order to validate the reactor inherent safety properties. Thus, the analysis of the response law of the power to the inserted reactivity is of great importance for the safety analysis and operating administration of the nuclear reactor. The point reactor kinetics equations are a system of coupled non-linear ordinary differential equations. The stiffness is the essential difficulty in solving these equations numerically [1]. As pointed out by many authors, this system of point kinetics equations remains an important set of equations. Reactivity - initiated accident is a nuclear reactor accident that involves inadvertent removal of control element from an operating reactor, thereby causing a rapid power excursion in the nearby fuel elements and temperature. The postulated scenarios for reactivity - initiated accidents are therefore focused on few events, which result in exceptionally large reactivity excursions, and therefore are critical to fuel integrity. In a reference model [2], reactivity, initiated accident was considered to be due to negative temperature feedback. In the present work we considered reactivity accident to be due to negative temperature feedback and the positive reactivity of control rods withdrawal at start-up and full power conditions. By analyzing accidents in a thermal reactor, modular high temperature

DOI : 10.14810/ijrap.2014.3202 
gas cooled reactor design like HTR-M [2], and using the stiffness confinement method for solving the kinetic equations. The stiffness confinement method (SCM) is used to solve the kinetics equations and overcome the stiffness problem in reactor kinetics [1]. The idea is based on the observation of stiffness characteristic, which is present only in the time response of the prompt neutron density, but not in the delayed neutron precursors. The method is therefore devised to have the stiffness decoupled from the differential equation for precursors and is confined to the one for prompt neutrons, which can be solved [1]. Numerical examples of applying the method to a variety of problems are given. The method is also used to analyze the reactivity induced accidents in thermal reactor data, modular high temperature gas cooled reactor (HTR-M) which is fuelled by uranium -235 at start-up and full power conditions [2]. In the next sections we discuss the mathematical method; present the results, discussion, and give the conclusion.

\section{MATHEMATICAL METHOD}

The stiffness confinement method is used to overcome the stiffness problem in reactor kinetics for solving the point kinetics equations. The idea is based on the observation, that the stiffness characteristic is present only in the response time of the prompt neutron density, but not in that of the delayed neutron precursors. The method is, therefore, devised to have the stiffness decoupled from the differential equations for the precursors and confine it to the one for the prompt neutrons, which can be analytically solved [1]. The point kinetics equations are a system of coupled ordinary differential equations, whose solution give the neutron density and delayed neutrons precursor concentrations in a tightly coupled reactor as a function of time. Typically, these equations are solved using the reactor model with at least six delayed precursor groups, resulting in a system consisting of seven coupled differential equations. Obtaining accurate results is often problematic, because the equations are stiff with many techniques, where very small time steps are used. These equations take the following form with an arbitrary reactivity function [3, 4]:

$$
\begin{aligned}
& \frac{d n(t)}{d t}=\frac{\rho(t)-\beta}{\Lambda} n(t)+\sum_{i=1}^{6} \lambda_{i} C_{i}(t) \\
& \frac{d C_{i}(t)}{d t}=\frac{\hat{\beta}_{i}}{\Lambda} n(t)-\lambda_{i} C_{i}(t)
\end{aligned}
$$

where: $n(t)$ is the time-dependent neutron density, or (power or neutron flux) all units are (MW) as power unit; $\mathrm{Ci}(t)$ is the $i^{\text {th }}$ group delayed neutron precursor concentration or delayed neutron emitter population or precursor density ("latent-neutron" density or latent power; same units as in the power); $i$ is the number of precursor group; $\rho(t)$ is the time-dependent reactivity; $\beta_{i}$ is $i^{\text {th }}$ group delayed neutron fraction, and $\beta=\Sigma_{i} \cdot \beta_{i}$, is the total delayed neutron fraction. In addition, $\Lambda$ is the neutron generation time (s) and $\lambda_{i}$ is decay constant of the ith-group delayed neutron emitters $\left(\mathrm{s}^{-1}\right)$.

Introducing a set of "Reduced" precursor density functions $\hat{C} i(t)$ and neutron density $n(t)$, through the following equation [1]:

$$
C_{i}(t)=\hat{C}_{i}(t) \exp \left[\int_{0}^{t} u\left(t^{\prime}\right) d t^{\prime}\right]
$$

Defining two auxiliary functions $w(t)$ and $u(t)$, as in Eqs. (4) and (5):

$$
w(t)=\frac{d}{d t} \ln n(t)
$$


The function $w(t)$ is defined in the same way as Eq. (9) below and provides the mechanism key of the SCM. The function $u(t)$, however, has nothing to do with stiffness decoupling and is not really required theoretically. Since an exponential behaviour is often characteristic for the first, order differential equations, however, a proper choice of $u(t)$ may make $\hat{C} i(t)$ vary more slowly in time and thus expedite the numerical calculation. Choose the following $u(t)[1]$ :

$$
u(t)=\frac{d}{d t} \ln S(t)
$$

Where, $S(t)$ is defined by Eq. (7) as the sum over all $\lambda i \cdot C i(t)$. We can rewrite Eqs. (1) and (2) as follows [1]:

$$
\begin{aligned}
& \frac{d \hat{C}_{i}(t)}{d t}=\left[\frac{\beta_{i}}{\Lambda w(t)+\beta-\rho(t)}\right] \sum_{i=1}^{6} \lambda_{i} \hat{C}_{i}(t)-\left[u(t)+\lambda_{i}\right] \hat{C}_{i}(t) \\
& S(t)=\left[\sum_{i=1}^{6} \lambda_{i} \hat{C}_{i}(t)\right] \exp \left[\int_{0}^{t} u\left(t^{\prime}\right) d t^{\prime}\right]
\end{aligned}
$$

And,

$$
\frac{d n(t)}{d t}=\frac{\rho(t)-\beta}{\Lambda} n(t)+S(t)
$$

Suppose that, it is always possible to express:

$$
n(t)=\exp \left[\int_{0}^{t} w\left(t^{\prime}\right) d t^{\prime}\right]
$$

And rewrite Eq. (1) as:

$$
n(t)=\frac{\sum_{i=1}^{6} \lambda_{i} C_{i}(t)}{\left(w(t)+\left[\frac{\beta-\rho(t)}{\Lambda}\right]\right)}
$$

Eqs. (6)- (9), form the complete set of kinetics equations for the SCM. The initial conditions are satisfied to be:

$$
\begin{gathered}
u(0)=0 \\
w(0)=\frac{\rho(0)}{\Lambda} \\
n(0)=n_{0}
\end{gathered}
$$




$$
\text { And, } \quad \hat{C}_{i}(0)=\frac{n_{0} \beta_{i}}{\Lambda \lambda_{i}}
$$

By using the initial conditions, we can obtain the numerical solution of the equations. We first start by setting $w$ and $u$ in Eq. (7) at their initial values and solves Eq. (7) for $\hat{C} i$ by discretizing the equation in $t$. Having obtained $\hat{C} i$, we calculate $S(t)$ with Eq. (1). Then, we use Eq. (5) to reevaluate $w(t)$, plug it back into Eq. (7), and repeat the process until $w$ converges (requiring 50 iterations). Calculation for the current time step is then finished with an evaluation of the output value of $w$ and $u$ via Eqs. (5) and (10). We continue to predict the input values of $w$ and $u$ for the next time step by linear extrapolation from their output values in the previous and current time steps, and repeat the whole process of calculation for the next time step. It should be emphasized that within each time step, there is iteration to convergence on $w$ but no iteration for the function $u$, because $u$ is not required by the theory of (SCM) and is, in principle, with an arbitrary independent function chosen only to expedite the computation. Computer program is designed with programming languages (FORTRAN and MATLAB) codes to solve the above equations numerically using Runge-Kutta method, and the output power and temperature are determined under different input reactivities. [15], [16], and [17]

It is assumed that, the reactor has a negative temperature coefficient of reactivity $\alpha(\alpha>0)$, when a large step reactivity $\rho_{0}\left(\rho_{0}>\beta\right)$ is inserted. Consider the temperature feedback, the real reactor reactivity is: $[3,4]$

$$
\rho(t)=\rho_{0}-\alpha\left[T(t)-T_{0}\right]
$$

Then, the derivative of Eq. (11) with respect to time (t) is:

$$
\frac{d \rho(t)}{d t}=-\alpha \frac{d T(t)}{d t}
$$

Where, $T(t)$ and $T_{0}$ are the reactor temperature, and initial temperature of the reactor, respectively. After the large reactivity $\rho_{0}$ is inserted into the reactor, the power responds quickly and the adiabatic mode can be used for the calculation of reactor temperature. [3, 4] Then, the derivative of the temperature with respect to time can be given as follows: [17]

$$
\frac{d T(t)}{d t}=K_{c} n(t)
$$

Where, $\mathrm{K}_{\mathrm{c}}$ is the reciprocal of thermal capacity of reactor. Substituting Eq. (12) into Eq. (13) results in the following:

$$
\frac{d \rho(t)}{d t}=-\alpha K_{c} n(t)
$$

\section{NUMERICAL SOLUTIONS}

The numerical solution of the point kinetics equations is based on SCM. The SCM is tested with three types of problems which are: [15], [17]

(1) Step reactivity,

(2) Ramp input Reactivity,

(3) Sinusoidal input Reactivity. 
The results are compared against solutions obtained by other methods. The other methods are highly accurate, but there vary widely in there complexity of implementation [1]. The compared methods are Henry's $\theta$, weighted method [6], Exact data obtained with Ref. [2], and Taylor Series Methods [5, 7], CORE [8], Mathematica's built-in differential equation solver (implicit Runge-Kutta). Each of these methods is highly accurate, but they vary widely in their complexity of implementation.

\subsection{Step Reactivity Insertion}

Considering a kinetic problem with step reactivity insertion with $\beta=0.007$.In this case, $\rho(t)=\rho_{0}$ for $t \geq 0$. The following input parameters were used: $\lambda i\left(\mathrm{~s}^{-1}\right)=(0.0127,0.0317,0.155,0.311,1.4$, $3.87), \beta i=(0.000266,0.001491,0.001316,0.002849,0.000896,0.000182)$ and $\Lambda=0.00002 \mathrm{~s}$. Four step reactivity insertions are considered: two prompt subcritical $\rho=0.003$ and 0.0055 , one prompt critical $\rho=0.007$, one prompt supercritical $\rho=0.008[2,8]$. The values of $n(t)$ obtained with the present work are compared (Table 1) with those obtained with a code based on the socalled "Henry's $\theta$, weighted method", which modifies finite difference equations by introducing tactically chosen weighting functions. The step size taken was $h_{l}=0.001$. For comparison, we chose "Henry's $\theta$, weighting method", and the exact values that obtained from Ref. [2] with the present results. The numbers presented in Table 1 are computed with time steps $(1 \mathrm{~s}, 10 \mathrm{~s}$ and 20 s).The results indicate that the present model solutions are in good agreement with all results. The iteration in computing was used for repeating the process until $w$ and $u$ converge (requiring approximately 100 iterations) to get step reactivity insertion with accurate results which are compared with several methods. [17]

Table 1 Comparison of present work and different methods for step reactivity insertion.

\begin{tabular}{|c|c|c|c|c|}
\hline \multirow[t]{2}{*}{$\overline{\rho \rho}$} & \multirow[t]{2}{*}{ Method } & \multicolumn{3}{|c|}{$n(t)$} \\
\hline & & $t=1 s$ & $t=10 s$ & $t=20 s$ \\
\hline 0.003 & $\begin{array}{c}\text { Present Results } \\
\theta \text {-Weighting } \\
\text { Chao and Attard } \\
\text { Exact }\end{array}$ & $\begin{array}{l}2.1849 \\
2.1737 \\
2.2254 \\
2.2098\end{array}$ & $\begin{array}{l}7.89116 \\
8.0069 \\
8.0324 \\
8.0192 \\
\end{array}$ & $\begin{array}{c}27.8266 \\
28.076 \\
28.351 \\
28.297 \\
\end{array}$ \\
\hline \multirow[b]{2}{*}{0.0055} & \multirow[b]{2}{*}{$\begin{array}{c}\text { Present Results } \\
\theta \text {-Weighting } \\
\text { Chao and Attard } \\
\text { Exact }\end{array}$} & $\mathrm{t}=0.1 \mathrm{~s}$ & $t=2 s$ & $t=10 s$ \\
\hline & & $\begin{array}{l}5.16136 \\
5.19450 \\
5.20570 \\
5.21000 \\
\end{array}$ & $\begin{array}{l}42.5859 \\
42.6520 \\
43.0240 \\
43.0250 \\
\end{array}$ & $\begin{array}{l}1.37302+05 \\
1.38820+05 \\
1.38750+05 \\
1.38860+05 \\
\end{array}$ \\
\hline \multirow[b]{2}{*}{0.007} & \multirow[b]{2}{*}{$\begin{array}{c}\text { Present Results } \\
\theta \text {-Weighting } \\
\text { Chao and Attard } \\
\text { Exact }\end{array}$} & $t=0.01 s$ & $t=0.5 \mathrm{~s}$ & $t=2 s$ \\
\hline & & $\begin{array}{l}4.44702 \\
4.50891 \\
4.50013 \\
4.50882\end{array}$ & $\begin{array}{l}53.0908+02 \\
53.4840+02 \\
53.5302+02 \\
53.4593+02\end{array}$ & $\begin{array}{l}20.4510+10 \\
20.6410+10 \\
20.6270+10 \\
20.5912+10\end{array}$ \\
\hline \multirow[b]{2}{*}{0.008} & \multirow[b]{2}{*}{$\begin{array}{c}\text { Present Results } \\
\theta \text {-Weighting } \\
\text { Chao and Attard } \\
\text { Exact }\end{array}$} & $t=0.01 s$ & $t=0.1 \mathrm{~s}$ & $t=1 s$ \\
\hline & & $\begin{array}{l}6.14858 \\
6.20300 \\
6.20460 \\
6.20291\end{array}$ & $\begin{array}{l}1.17679+03 \\
1.41150+03 \\
1.40891+03 \\
1.41042+03\end{array}$ & $\begin{array}{l}6.0564+23 \\
6.2258+23 \\
6.1574+23 \\
6.1634+23\end{array}$ \\
\hline
\end{tabular}

Another example to the numerical solution of the point kinetics equations is based on (SCM), is the prompt super-critical process at large step reactivity. [17] The results are highly accurate, but vary widely in their complexity of implementation. As, explained in section (2) about the point 
kinetics equations (1-10), and the negative temperature coefficient of reactivity in Eqs. (11-14), at the time $t=0$, large step reactivity, $\rho_{0}\left(\rho_{0}>\beta\right)$ is suddenly inserted in the reactor, and the prompt super-critical process will appear. During this process, the reactor power varies very quickly and the power increase is up to very high level, so at time $t>0$ the contribution of the neutron source of delayed neutron precursors may be neglected, and is simplified as: [10], [11], [12], and [13]

$$
\frac{d n(t)}{d t}=\frac{\rho(t)-\beta}{\Lambda} n(t)
$$

Consider the prompt super-critical process with $\mathrm{U}^{235}$ as fissile material under large step increases in reactivity of $2 \beta$ and $1.5 \beta$, after operating in the steady state, respectively. By considering the point kinetic equations are with one group of delayed neutrons. The one-group delayed neutron parameters are: $\beta_{t o t}=0.0065, \Lambda=0.0001(\mathrm{sec}), \lambda=0.07741\left(\mathrm{sec}^{-1}\right), K_{c}=0.05 \mathrm{~K} /(\mathrm{MW} \mathrm{s}), \alpha=5 \times 10^{-5}$ $\mathrm{K}^{-1}$. For different initial power, that are $(10,1,0.1$ and 0.01$) \mathrm{MW}$, respectively, the variation curves of reactivity and power as well as temperature increase with time, and variation curves of power with reactivity are plotted in Figures (3.1-3.4), in which 1 denotes only the effect of prompt neutrons and $\mathbf{2}$ the effect of both prompt neutrons and delayed neutrons, and the real and dashed lines denote inserting step reactivity $\rho_{0}=(1.5 \beta$, and $2 \beta)$, respectively. For each group of curves in Figures (1-4), from the left to right the initial power is $(10,1,0.1$ and 0.01$)$ MW, respectively.

In Figure (1), is found that, while inserting large step reactivity into the reactor, the total reactivity firstly decreases slowly with time and then drops quickly to steady level.

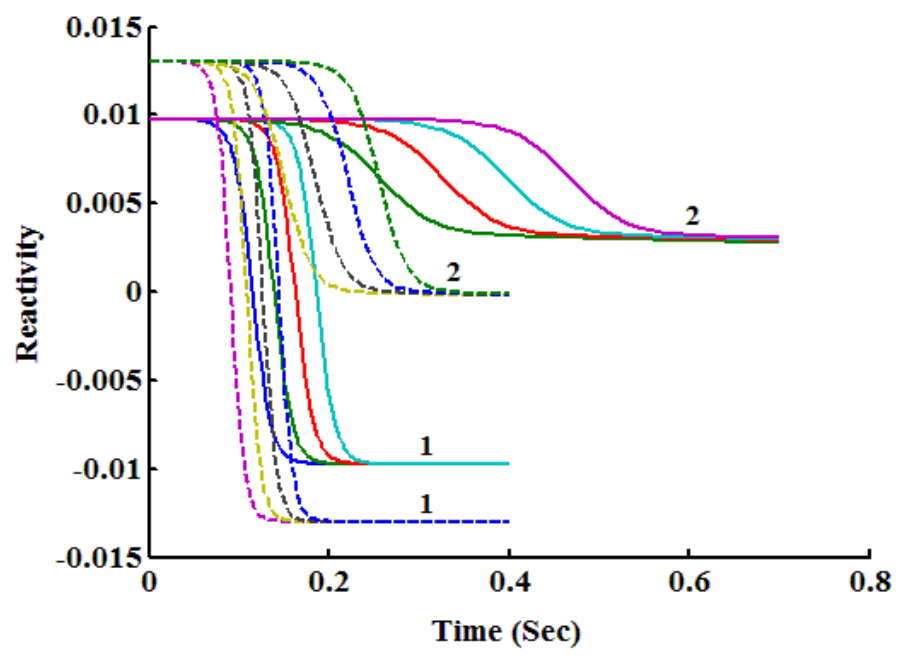

Figure (1): Variation of total reactivity with time while inserting large step reactivity into reactor.

Figure (2) illustrates that, power of prompt super-critical process increases acutely, and the maximum value of power is always larger than the initial power. It can be seen from Figure (2) that, the excursion of reactor power $n$ is related to the initial power, and the step reactivity inserted. 


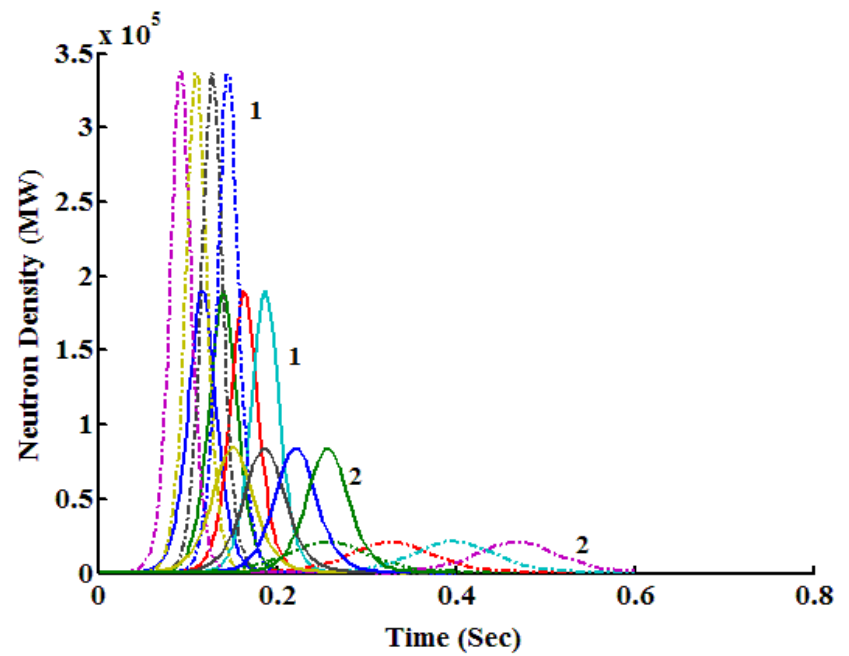

Figure (2): Variation of output power with time while inserting large step reactivity into reactor.

Figure (3) shows the variation curve of the reactor power $n$ versus $\rho$. The variation curve with larger $\rho_{0}$ lays over those with smaller $\rho_{0}$, but reactivity related to the maximum power has the same value. Compared with the power increase in the transient process, the initial power is much smaller, so in figure (3) the curves with the same $\rho_{0}$ but different initial power pose each other.

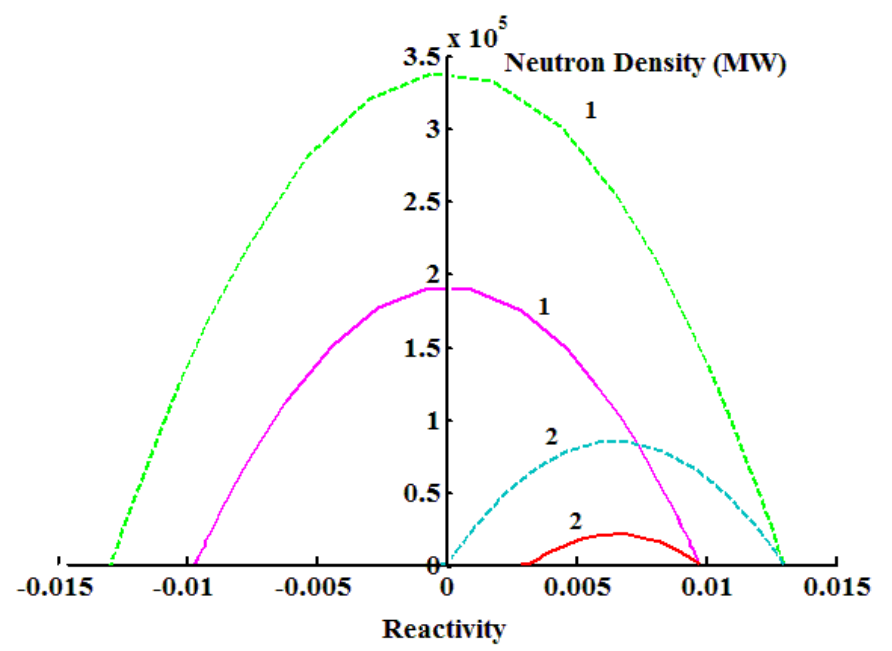

Figure (3) : Variation of output power with reactivity while inserting large step reactivity into reactor.

Figure (4) indicates that, temperature firstly increases slowly with time, and rises suddenly and tends to be steady at the end. 


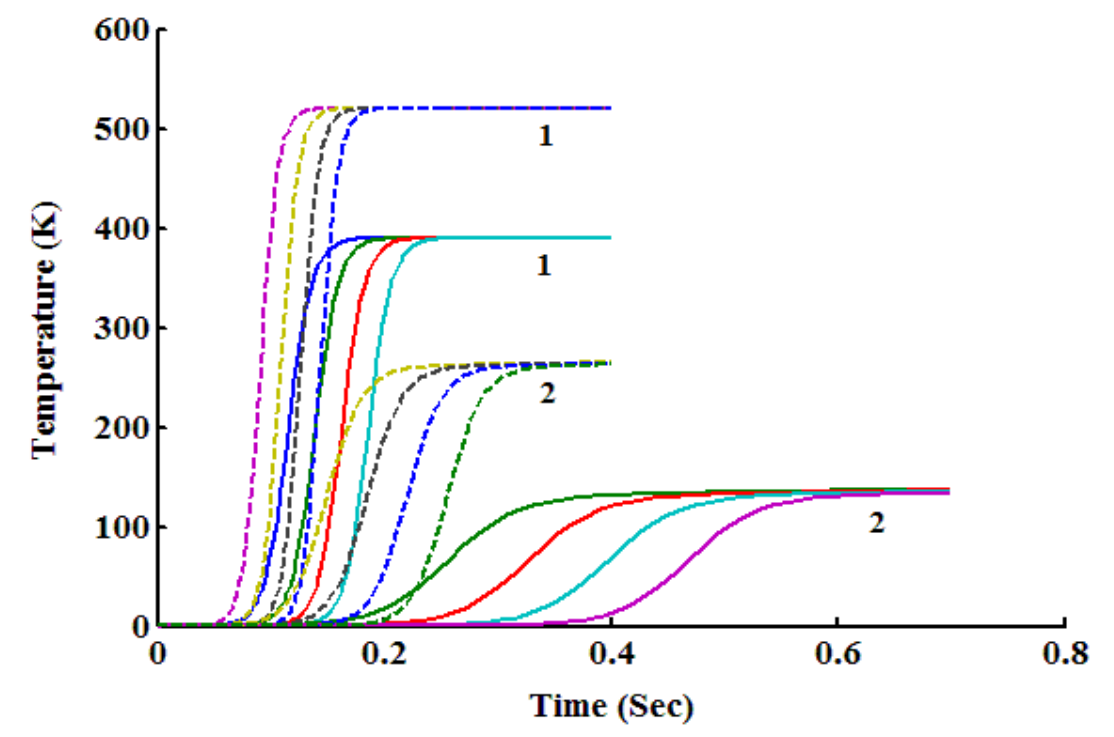

Figure (4) : Variation of temperature increase with time while inserting large step reactivity into reactor.

In this case, analyzing the delayed supercritical process of a nuclear reactor with temperature feedback and initial power while inserting small step reactivity, we obtained the variations of total reactivity and output power with time as well as the variation of output power with reactivity. It is assumed that, the reactor has a negative temperature coefficient of reactivity $\alpha(\alpha>0)$, when small step reactivity $\rho_{0}\left(\rho_{0}<\beta\right)$ is inserted, as mentioned in the previous example of large step reactivity.

Consider the delayed supercritical process with small step inserted reactivity of $\rho_{0}=(\beta / 4$, and $\beta / 1.2)$ of ${ }^{235} \mathrm{U}$ as fissile material, respectively. It is assumed that, $\beta=0.0065, \Lambda=0.0001(\mathrm{sec}), \lambda=$ $0.07741\left(\mathrm{sec}^{-1}\right), K_{c}=0.05(\mathrm{~K} / \mathrm{MW} \mathrm{s}), \alpha=5^{*} 10^{-5}\left(\mathrm{~K}^{-1}\right)$, and the initial power is $(10,1$ and 0.01$)$ (MW). The variation curves of reactivity, temperature, and power with time, as well as the variation curves of power with reactivity under different initial power are plotted in Figures (5$12)$.

\section{- First case at $\rho_{0}=(\beta / 4)$}

Figure (5) illustrates that, the power of the delayed supercritical process firstly increases acutely, then decreases slowly with time, and drops quickly to a steady level. 


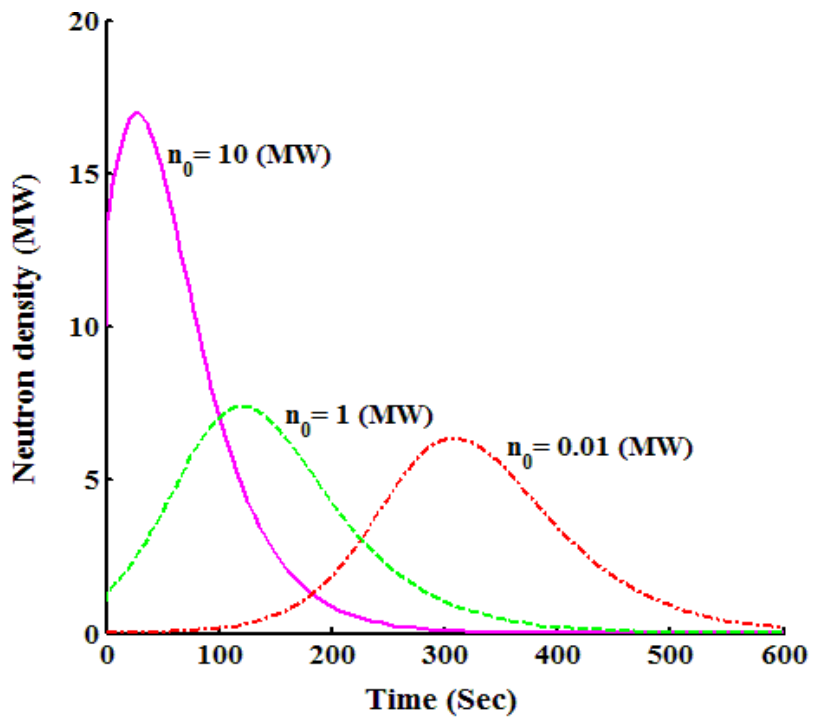

Figure (5):Variation of output power with time while inserting small step reactivity $\left(\rho_{0}=\beta / 4\right)$ into reactor.

In Figure (6), is observed that, while inserting small step reactivity into the reactor, the total reactivity firstly decreases slowly with time and then drops quickly to a steady level.

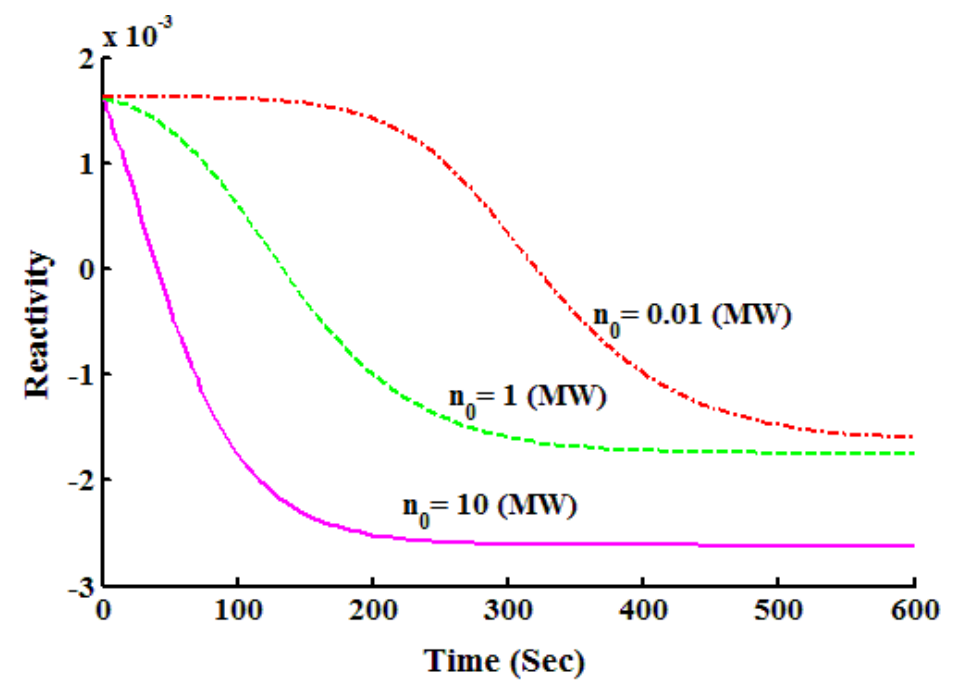

Figure (6) :Variation of total reactivity with while inserting small step reactivity $\left(\rho_{0}=\beta / 4\right)$ into reactor.

Figure (7) shows the variation curve of reactor power $n$ versus $\rho$. The variation curve with small $\rho_{0}$, out power increases quickly and decreases slowly with time at inserting small step reactivity and then drops quickly. 


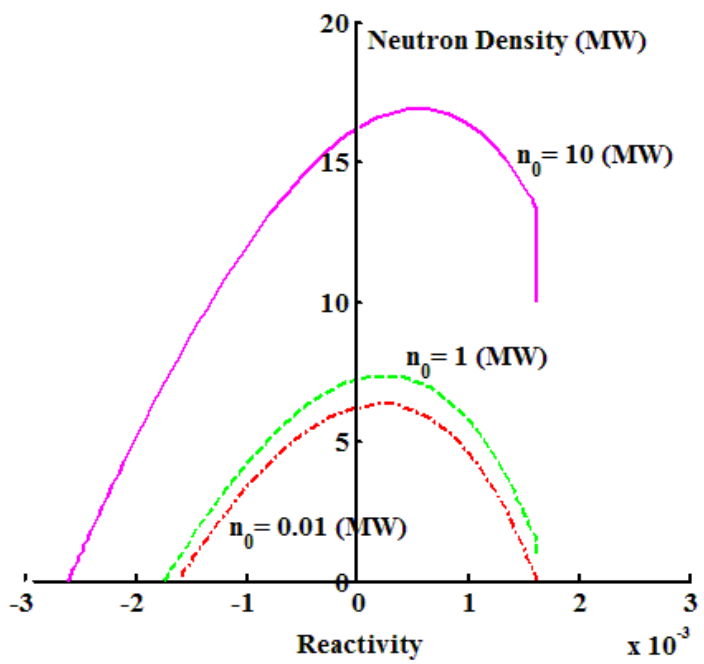

Figure (7) :Variation of output power with reactivity while inserting small step reactivity $\left(\rho_{0}=\beta / 4\right)$ into reactor.

Figure (8) indicates that, temperature firstly increases slowly with time, and suddenly tends to be steady at the end.

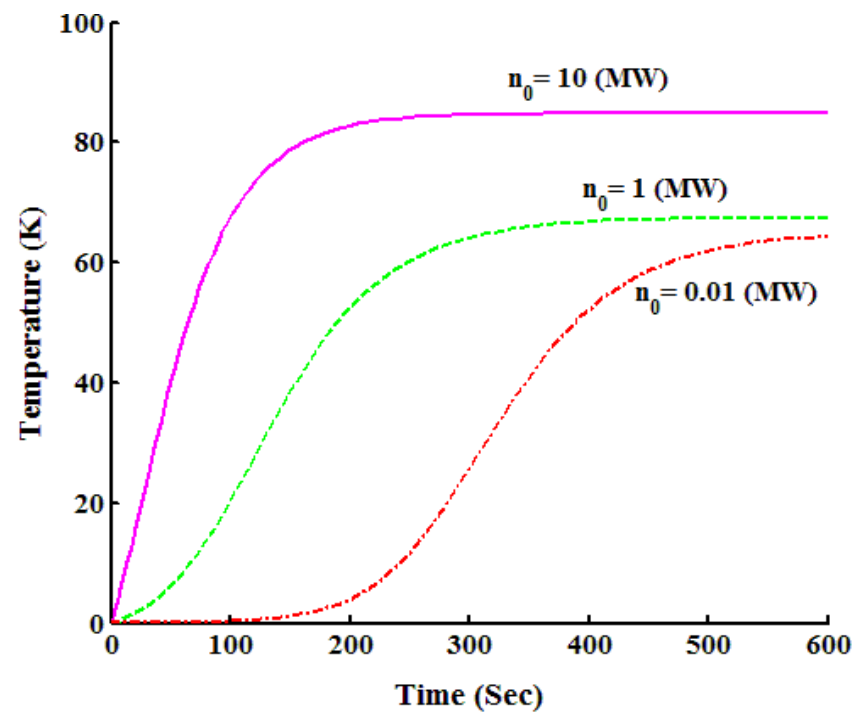

Figure (8) : Variation of temperature with time while inserting small step reactivity $\left(\rho_{0}=\beta / 4\right)$ into reactor.

\section{* Second case at $\rho_{0}=(\beta / 1.2)$}

Figure (9) illustrates that the power of the delayed supercritical process firstly increases rapidly, then decreases slowly with time, at different initial power conditions until it approaches saturation. 


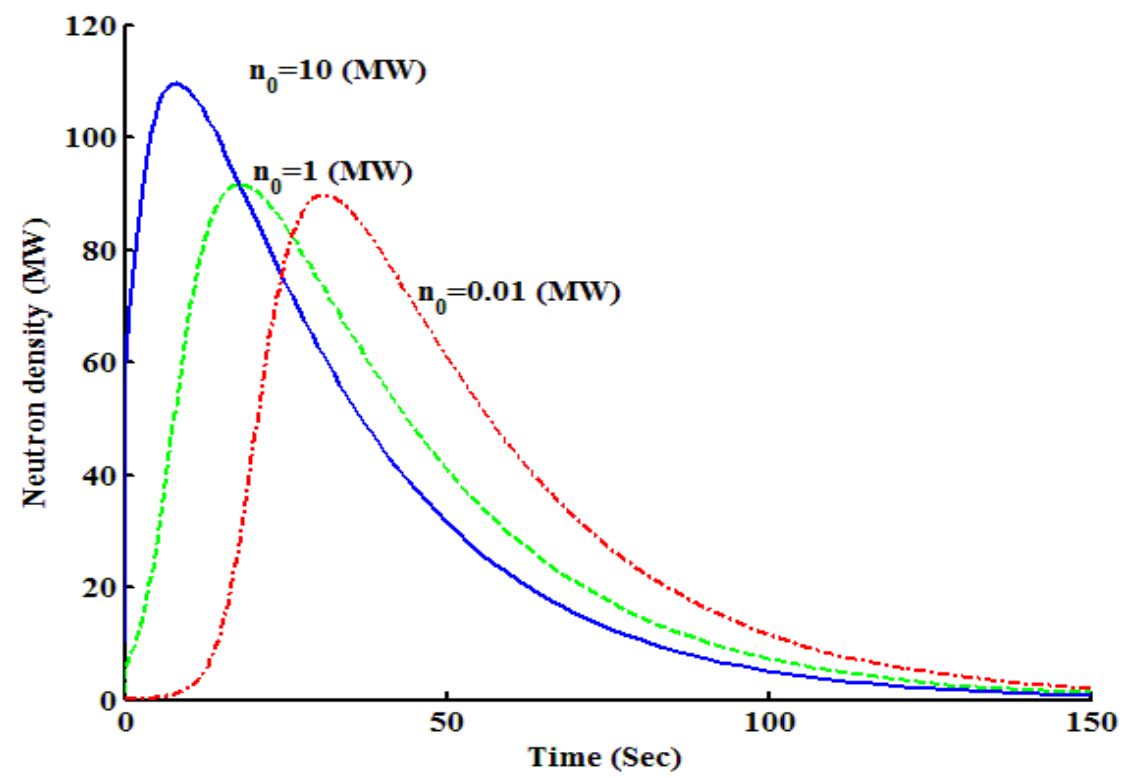

Figure (9):Variation of output power with time while inserting small step reactivity $\left(\rho_{0}=\beta / 1.2\right)$ into reactor.

In Figure (10), it is found that, while inserting small step reactivity into the reactor, the total reactivity firstly decreases slowly with time from positive part and then drops quickly to negative part and goes to a steady level.

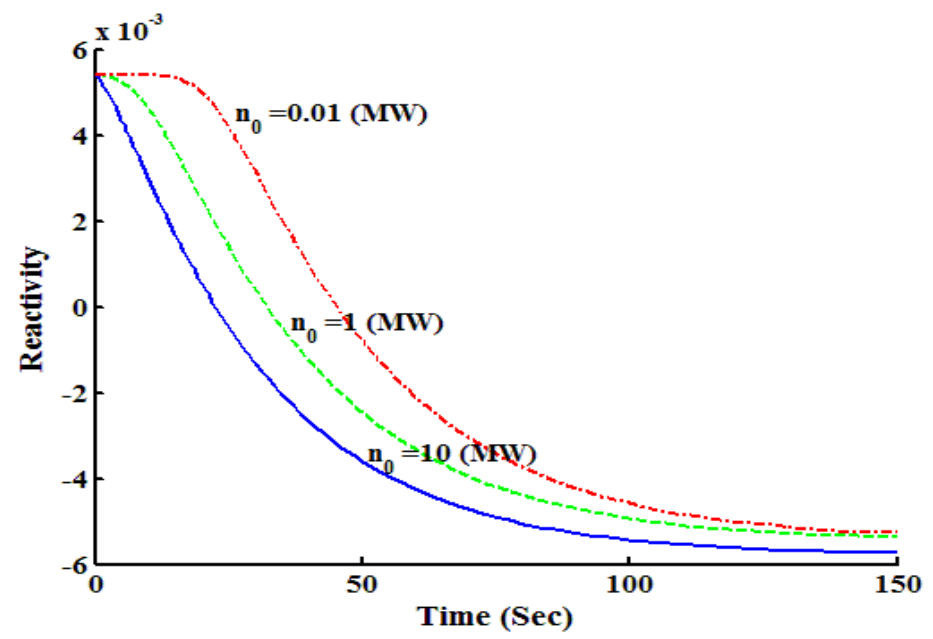

Figure (10):Variation of total reactivity with while inserting small step reactivity $\left(\rho_{0}=\beta / 1.2\right)$ into reactor.

Figure (11) shows the variation curve of the reactor power $n$ versus $\rho$. The variation curve with small $\rho_{0}$, reactor power increases quickly and decreases slowly with time at inserting small step reactivity and then drops quickly. 


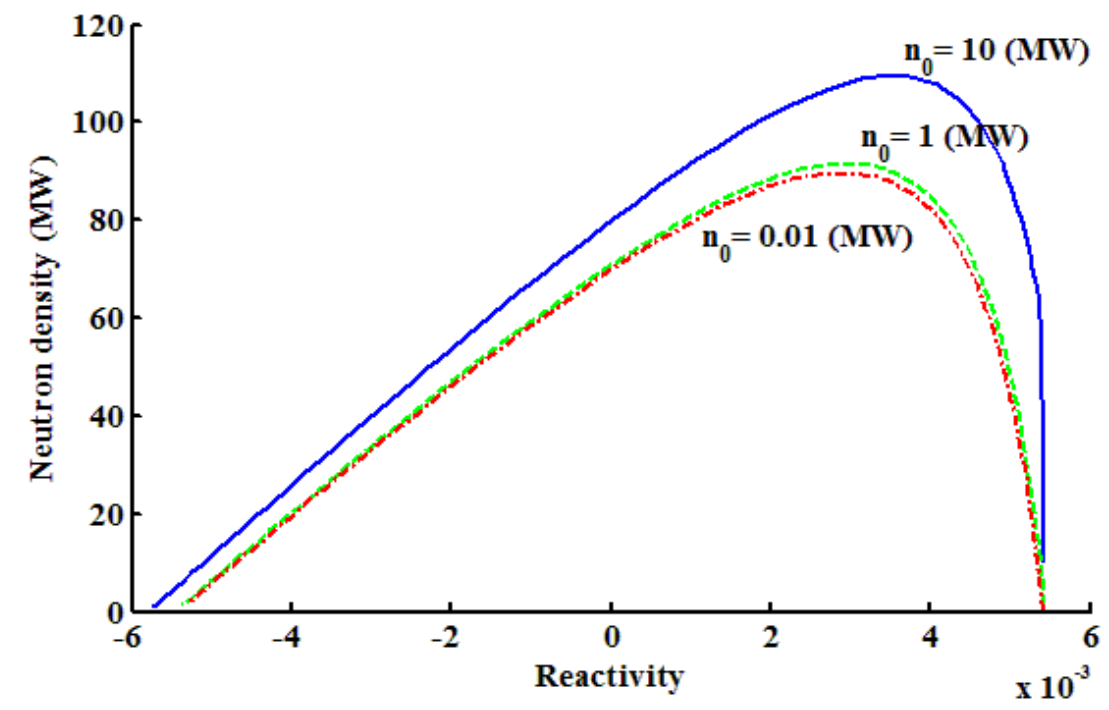

Figure (11):Variation of output power with reactivity while inserting small step reactivity $\left(\rho_{0}=\beta / 1.2\right)$ into reactor.

Figure (12) indicates that, temperature firstly increases rapidly with time because of inserting small step reactivity, and suddenly tends to be steady at the end.

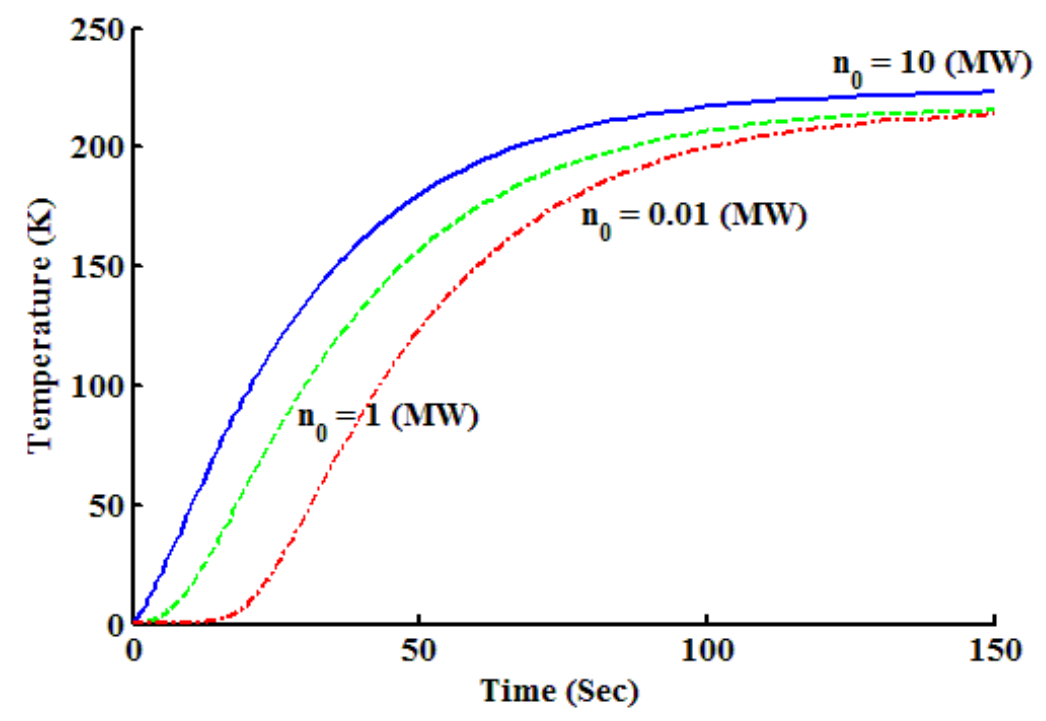

Figure (12):Variation of temperature with time while inserting small step reactivity $\left(\rho_{0}=\beta / 1.2\right)$ into reactor.

\subsection{Ramp Input of Reactivity}

Consider now the two cases of ramp input. Ramp reactivity usually takes the form:

$$
\rho(t)=\rho_{0} t
$$

Where, $\rho_{0}=\rho / \beta$ is a given reactivity expressed in dollars $[9,10]$.We will use the same parameters, which are used in the step reactivity example, and compare our results with those of Ref. [1]. The first case is extremely fast and the second is moderately fast. In the first one, it can be seen that, 
the response of reactor core at $0.001 \mathrm{~s}$ after a ramp input of reactivity at the rate of $\$ 100 / \mathrm{s}$ is calculated (with six results for this case are presented in Table 2 in groups of delayed neutron). The comparison of the SCM solution in Ref. [1] with others methods are accurate. The second case is a (moderately fast) ramp of $\$ 0.01 / \mathrm{s}$ to reactor core. The values of the physical parameters are the same as those of step reactivity insertion examples. The computational results for this case are presented in Table 3 along with other methods. The iteration in computing was used for repeating the process until $w$ and $u$ converge (requiring 10 iterations) to take ramp reactivity insertion which is a time dependent function with small time step in order to get accurate results in comparison with several methods. [15], [17]

Table 2 Comparison of Present Work and SCM in Ref. [1] for ramp input reactivity at the first case: (extremely fast).

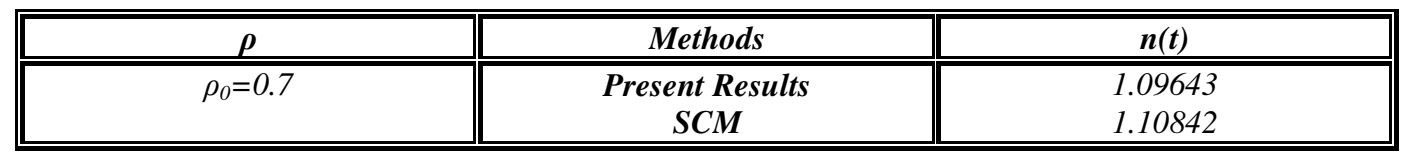

Table 3 Comparison of Present Work and SCM in Ref. [1] for ramp input reactivity at the second case: (moderately fast).

\begin{tabular}{||l||c|c|c|c|c||}
\hline \multicolumn{1}{|c|}{ Methods } & $\boldsymbol{t}=\mathbf{2} \boldsymbol{s}$ & $\boldsymbol{t}=\mathbf{4} \boldsymbol{s}$ & $\boldsymbol{t}=\mathbf{6} \boldsymbol{s}$ & $\boldsymbol{t}=\mathbf{8} \boldsymbol{s}$ & $\boldsymbol{t}=\mathbf{9} \boldsymbol{s}$ \\
\hline \hline Presents Results & 1.32081 & 2.19494 & 5.49151 & $4.20720+01$ & $4.79378+02$ \\
\hline \hline $\boldsymbol{\theta}$-Weighting & 1.33832 & 2.22903 & 5.58852 & $4.32151+01$ & $5.06363+02$ \\
\hline \hline SCM & 1.33824 & 2.22842 & 5.58191 & $4.27882+01$ & $4.87814+02$ \\
\hline \hline Exact & 1.33739 & 2.22832 & 5.58151 & $4.27800+01$ & $4.7452+02$ \\
\hline \hline
\end{tabular}

\subsection{Sinusoidal Input of Reactivity}

Consider the case of sinusoidal reactivity. In this case the kinetic parameters are used: $\lambda_{i}(\mathrm{~s}-1)$ $=\left(0.0124,0.0305,0.111,0.301,1.14\right.$ and 3.01), $\beta_{i}=(0.000215,0.001424,0.001274$, $0.002568,0.000748$, and 0.000273$), A=0.0005 \mathrm{~s}, T=5.00 \mathrm{~s}$ and $\beta=0.006502$. The reactivity is a time dependent function of the form Ref. [1, 5, and 9]:

$$
\rho(t)=\rho_{0} \sin \left(\frac{\pi t}{T}\right)
$$

Where, $T$ is a half-period and $\rho_{0}=\beta$.The results of the present method are compared with other methods in Table 4 and showed a good agreement. The iteration in the computation, is used for repeating the process until $w$ and $u$ converge (requiring 100 iterations) to get step reactivity insertion with accurate results. The iteration in computing is used for repeating the process until $w$ and $u$ converge (requiring 10 iterations) to take sinusoidal reactivity insertion which is a triangular function inside it half period and small time step to get accurate results. The results are compared with several methods.

Table 4 Comparison of present work and other methods for sinusoidal reactivity.

\begin{tabular}{||c||c|c||c|c||}
\hline $\boldsymbol{t}($ Sec $)$ & Present Work & Taylor & Core & Mathematica \\
\hline \hline $\mathbf{2}$ & 11.320 & 11.3820 & 10.1475 & 11.3738 \\
\hline \hline $\mathbf{4}$ & 84.950 & 92.2761 & 96.7084 & 92.5595 \\
\hline $\mathbf{6}$ & 15.4824 & 16.0317 & 16.9149 & 16.0748 \\
\hline $\mathbf{8}$ & 8.027237 & 8.6362 & 8.8964 & 8.6551 \\
\hline $\mathbf{1 0}$ & 12.1093 & 13.1987 & 13.1985 & 13.2202 \\
\hline
\end{tabular}


International Journal of Recent advances in Physics (IJRAP) Vol.3, No.2, May 2014

\section{ANALYSIS OF REACTIVITY- INITIATED -ACCIDENT}

\subsection{Reactivity- Initiated Accident}

Reactivity- initiated accident involves an unwanted increase in fission rate and reactor power. The power increase may damage the reactor core, and in very severe cases, even lead to the disruption of the reactor. The immediate consequence of reactivity- initiated accident is a fast rise in fuel power and temperature. The power excursion may lead to failure of the nuclear fuel rods and release of radioactive material into primary reactor coolant. The control rod insertion increases the thermalization of neutrons, and thus, results in a positive reactivity. So, the control rod insertion requires a certain driving force. The driving forces on the control rods in the HTR-M reactor are the buoyancy from the fuel and the supporting force from the control system of the reactor. If the control system should lose the support of the control rods or the control rods should break, the control rods would be flown out of the reactor. Thus, in the HTR-M reactor, accidental insertions can result from the malfunctions of the control rod drive mechanism and/or control rod control system. In this study, a new computer program has been developed for simulating the reactor dynamic behaviour during reactivity induced transients, and it has been used for the analysis of specified reactivity - initiated accidents in several cases. By introducing the model of reactor with system parameters that are characteristic for modular high temperature gas-cooled reactor design like HTR-M [11]. For simplicity, we refer to the input data of HTR-M reactors in tables (7, and 8).

Table $7{ }^{235} \mathrm{U}$ (Thermal Neutrons), (HTR-M Reactor)

\begin{tabular}{|c|c|c|c|c|c|c|}
\hline$\lambda_{i}\left(\mathbf{S e c}^{-1}\right)$ & 0.0124 & 0.0305 & 0.111 & 0.301 & 1.14 & 3.01 \\
\hline $\boldsymbol{\beta}_{i}$ & 0.000215 & 0.001424 & 0.001274 & 0.002568 & 0.0007485 & 0.0002814 \\
\hline \multicolumn{3}{|c|}{$\boldsymbol{\beta}_{\text {tot }}=0.0067$} & \multicolumn{4}{c|}{$\Lambda=1.00^{*} 10^{-4}(\mathrm{Sec})$} \\
\hline
\end{tabular}

Table 8 Adiabatic Inherent Shutdown Data of HTR-M Model Reactor.

\begin{tabular}{|c|c|c|c|}
\hline Types of Reactors & $\boldsymbol{n}_{\mathbf{0}}(\mathbf{M W})$ & $\boldsymbol{c}(\mathbf{M J} / \mathbf{K})$ & $\boldsymbol{\alpha}\left(\mathbf{K}^{-\mathbf{1}}\right)$ \\
\hline HTR-M & 200.00 & 100.00 & $2.2 * 10^{-5}$ \\
\hline
\end{tabular}

For the delayed neutron parameters, it is assumed that, HTR-M is fuelled by ${ }^{235} \mathrm{U}$ as fissile nuclide. The dynamic equations (16:21) for the model are the conventional point reactor kinetics equations in combination with a linear temperature feedback for the reactivity, an adiabatic heating of the core after loss of cooling [2], where Eq. (18 a) may be modified to the positive control rods reactivity as Eq. (18 b) to be as expressed in Eq. (20): [15], [16], and [17]

$$
\begin{aligned}
& \frac{d n(t)}{d t}=\frac{\rho_{\text {net }}(t)-\beta}{\Lambda} n(t)+\sum_{i=1}^{6} \lambda_{i} C_{i}(t) \\
& \frac{d C_{i}(t)}{d t}=\frac{\beta_{i}}{\Lambda} n(t)-\lambda_{i} C_{i}(t) \\
& \rho_{\text {feed }}=-\alpha\left(T(t)-T_{0}\right), \rho_{\text {feed }}=\text { feedback reactivity } \\
& \rho_{\text {ext }}=\rho_{C R}=\rho_{c r 1} \text { or } \rho_{c r 2}
\end{aligned}
$$




$$
\begin{aligned}
& \rho_{\text {ext }}=\text { external reactivity }=\text { control rods reactivity } \\
& \rho_{\text {net }}(t)=\rho_{\text {feed }}(t)+\rho_{\text {ext }}(t)
\end{aligned}
$$

$$
\begin{gathered}
\rho_{n e t}(t)=-\alpha\left(T(t)-T_{0}\right)+\rho_{C R} \\
\frac{d T(t)}{d t}=\frac{1}{c} n(t)
\end{gathered}
$$

\section{Where:}

$n(t)=$ reactor power $(\mathrm{MW}), \rho_{\text {net }}(t)=$ is the time-dependent reactivity function, $\rho_{C R}=$ Positive Reactivity of Control Rods Withdrawal, $\beta=$ total delayed neutron fraction, $\beta=\Sigma_{i} \beta_{i}$. $\beta_{i}=$ Delayed neutron faction of $\mathrm{i}^{\text {th }}$ group. $\Lambda=$ neutron generation time (sec), $\lambda_{i}$ decay constant of $\mathrm{i}^{\text {th }}$ group delayed neutron emitters $(\mathrm{sec})^{-1}, \mathrm{C}_{\mathrm{i}}(t)=$ delayed neutron emitter population (in power units), $\alpha=$ temperature coefficient of reactivity $\left(\mathrm{K}^{-1}\right), T=$ reactor temperature $(\mathrm{K}), T_{0}=$ critical reactor temperature $(\mathrm{K})$ and $c=$ heat capacity of reactor $(\mathrm{MJ} / \mathrm{K})$.

In the equation of total reactivity $\rho_{\text {net }}(t)$ and the positive reactivity of control rods withdrawal $\rho_{\text {cr }}$ has two cases to prevent the control rods withdrawal accident:

$$
\rho_{c r 1}=\rho_{1}=(\beta / 2), \rho_{c r 2}=\rho_{2}=(\beta)
$$

\subsection{Reactivity Addition at Full Power Condition for HTR-M Reactor}

HTR-M Reactor is assumed to be operating at equilibrium power condition [200 (MW)], and the limited value of time (Sec) on $x$ axis is 400 (Sec) at full power condition. Reactivity is added step by step. The full Power transients for one, and two control rods withdrawal are shown in figure (13). The control rods are withdrawal; the power pulse will be indicated in the two cases as explained in Eqs. (23-24).

The two cases of net reactivity after adding positive reactivity of the control rods are expressed as:

$$
\begin{aligned}
& 1-\rho_{1}(t)=-\alpha\left(T(t)-T_{0}\right)+(\beta / 2), \\
& 2-\rho_{2}(t)=-\alpha\left(T(t)-T_{0}\right)+(\beta) .
\end{aligned}
$$

First, with negative temperature feedback and the positive reactivity of control rods withdrawal $(\beta / 2)$, the maximum power ratio has increased by 23.69 times from the initial value of power at $t=9.355(\mathrm{Sec})$.

Second, with negative temperature feedback and the positive reactivity of the control rods withdrawal $(\beta)$, power ratio has increased by 53.50 times from the initial value of power at $t=0.706(\mathrm{Sec})$. Then, the power pulse increased many times of the rated power generated in a very short time. The result is that, the reactivity induced accident due to the control rods withdrawal. 


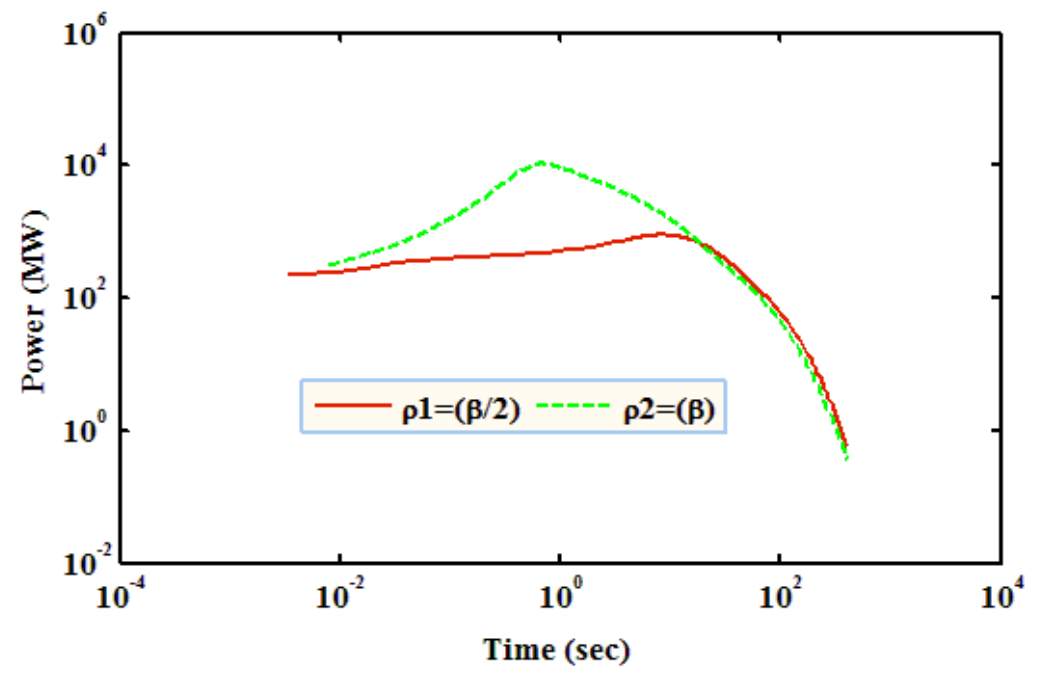

Figure 13: Shows Power (MW) Transient at Full Power Condition for HTR-M Reactor.

Figure (14) shows the temperature transients in the two cases of reactivity. Temperature is proportional with power in Eq. (21), and the net reactivity in Eq. (20). The power in Eq. (18) increases due to the positive reactivity of the control rods withdrawal in the net reactivity equation. The maximum temperature exceeded $998.4(\mathrm{~K})$ about $250(\mathrm{Sec})$.The results indicate that: the initial condition $t=0(\mathrm{Sec}), \mathrm{T}_{0}=350(\mathrm{~K})$, temperature increases, until $t=250(\mathrm{Sec})$, and becomes $T=476.4(\mathrm{~K})$, first case: $T=696.7(\mathrm{~K})$, second case: $T=982.5(\mathrm{~K})$. After $t=200(\mathrm{Sec})$, temperature approaches to saturation.

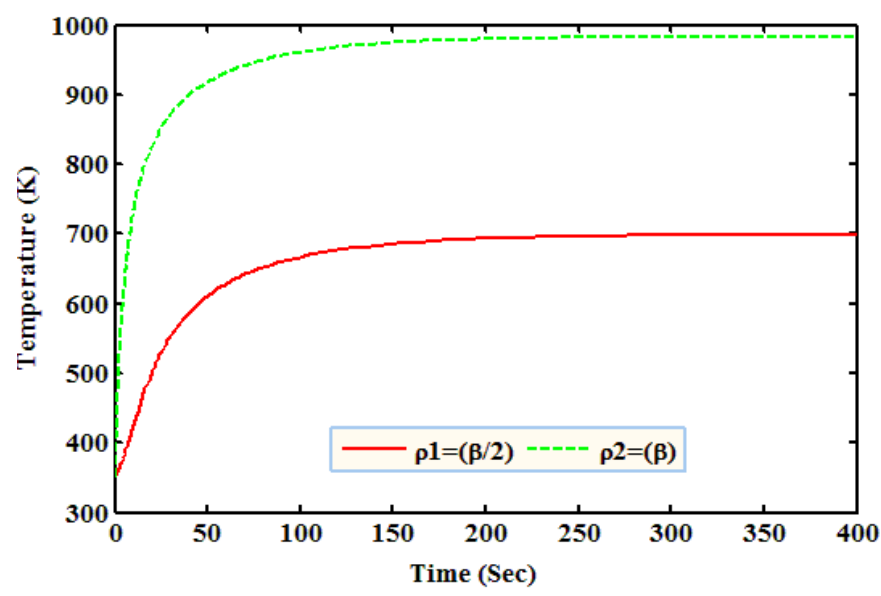

Figure 14: Shows Temperature (K) During The Transients at Full Power for HTR-M Reactor.

Figure (15) shows the reactivity transients in the four cases. Reactivity is proportional with temperature in Eq. 18(a,b), and the positive reactivity of the control rods withdrawal in the net reactivity in Eq. $(19,20)$. Reactivity is decreased due to the negative temperature feedback of the loss of cooling. The results indicate that: reactivity increases because of, the positive reactivity of the control rods withdrawal in the net reactivity equation.

In the first case (eq. (23)): reactivity is decreased from upper part to the below part. In the below negative part of this figure (15), reactivity is decreased due to the negative temperature feedback 
at $t=700(\mathrm{Sec}), \rho=\left(-4.3^{*} 10^{-3}\right)$.In the upper positive part, reactivity is increased due to the positive reactivity resulting of the control rods withdrawal at $t=20(\mathrm{Sec}), \rho=\left(+3.3^{*} 10^{-3}\right)$.

In the second case (eq. (24)): reactivity is decreased from upper part to the below part. In the below negative part of this figure, reactivity is decreased due to the negative temperature feedback at $t=200(\mathrm{Sec}), \rho=\left(-7.00^{*} 10^{-3}\right)$. In the upper positive part, reactivity is increased due to the positive reactivity resulting from the control rods withdrawal at $t=20(\mathrm{Sec}), \rho=\left(+6.50^{*} 10^{-3}\right)$. The results of figure (15) indicate that: in the two cases, the net reactivity decreases from positive to negative.

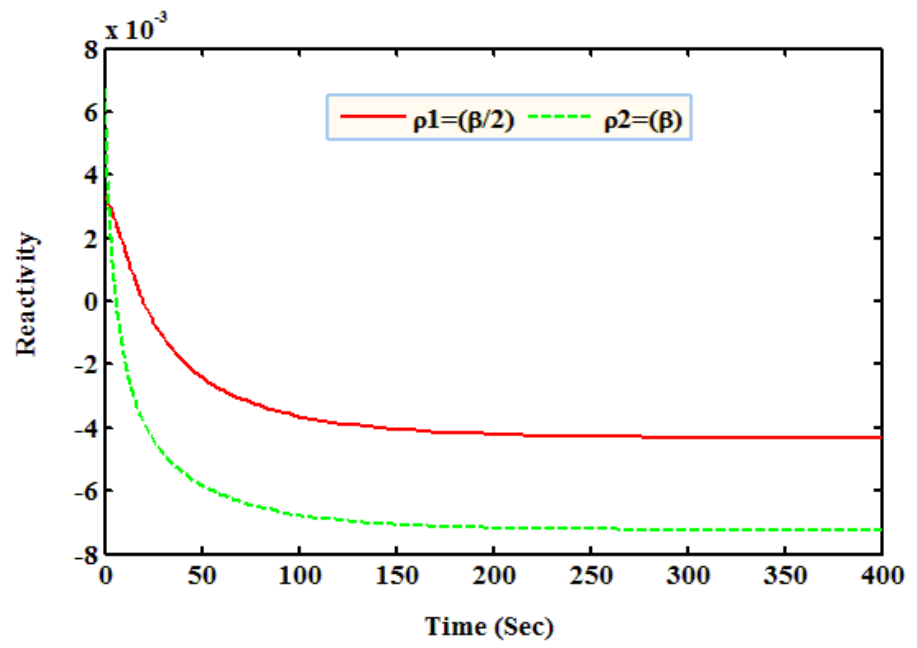

Figure 15 : Shows Reactivity Transients at Full Power Condition for HTR-M Reactor.

\subsection{Reactivity Addition at Startup Condition for HTR-M Reactor}

HTR-M Reactor is assumed to be operating at startup power condition [0.002 (MW)], and the limited value of time (Sec) on $x$ axis is 400 (Sec) at startup condition. Reactivity is added step by step. Power transients for one and two control rods withdrawal are shown in figure (16). The control rods are withdrawal; the power pulse will be indicated in the two cases as explained in Eqs. (23-24). [15], [17]

First, with negative temperature feedback and the positive reactivity of control rods withdrawal $(\beta / 2)$ at start-up condition, the maximum power ratio has increased by 25.635 times from the initial value of power at $t=9.355(\mathrm{Sec})$.

Second, with negative temperature feedback and the positive reactivity of the control rods withdrawal $(\beta)$, power ratio has increased by 42.90 times from the initial value of power at $t=0.706(\mathrm{Sec})$. Then, the power pulse increased many times of the rated power generated in a very short time due to the operation of thermal reactor at start-ups condition. The result is that, the reactivity induced accident due to the control rods withdrawal at start-ups condition. [17] 


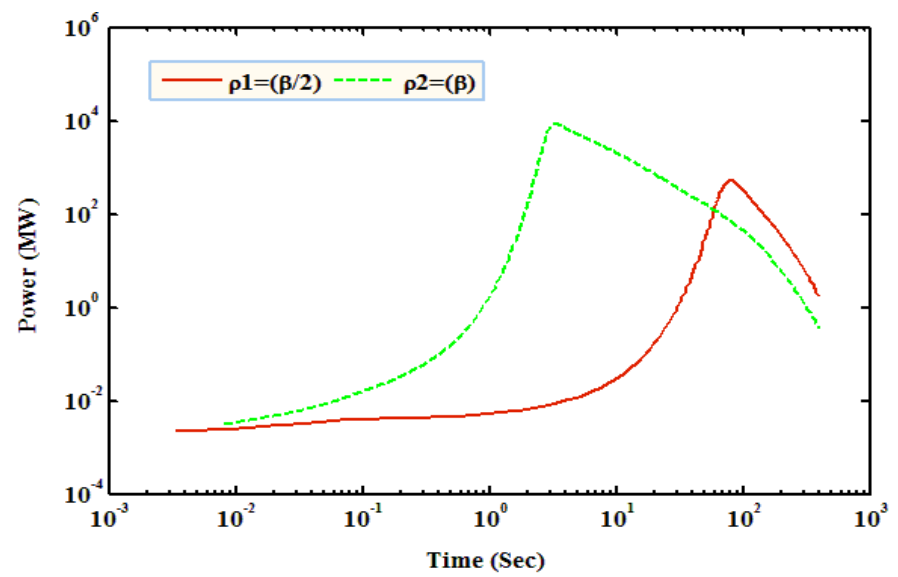

Figure 16 :Shows Power (MW)Transient at Starup Condition for HTR-M Reactor.

Figure (17) shows the temperature transients in the two cases of reactivity. Temperature is proportional with power in Eq. (21), and the net reactivity in Eq. (20). The power in Eq. (18) increases due to the positive reactivity of the control rods withdrawal in the net reactivity equation. The maximum temperature exceeded $889.4(\mathrm{~K})$ about $250(\mathrm{Sec})$.The results indicate that: the initial condition $t=0(\mathrm{Sec}), \mathrm{T}_{0}=300(\mathrm{~K})$, temperature increases, until $t=250(\mathrm{Sec})$, and becomes $T=476.4(\mathrm{~K})$, first case: $T=567.7(\mathrm{~K})$, second case: $T=854.5(\mathrm{~K})$. After $t=200(\mathrm{Sec})$, temperature approaches to saturation.

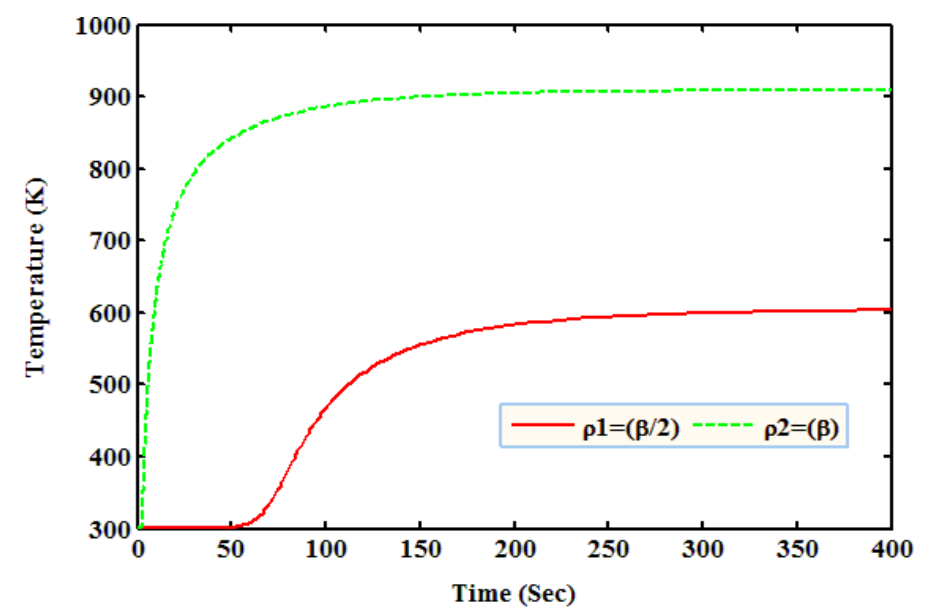

Figure 17: Shows Temperature (K) During The Transients at Starup Condition for HTR-M Reactor.

Figure (18) shows the reactivity transients in the four cases. Reactivity is proportional with temperature in Eq. 18(a, b), and the positive reactivity of the control rods withdrawal in the net reactivity in Eq. $(19,20)$. Reactivity is decreased due to the negative temperature feedback of the loss of cooling. The results indicate that: reactivity increases because of, the positive reactivity of the control rods withdrawal in the net reactivity equation.

In the first case (Eq. (23)): reactivity is decreased from upper part to below part. In the below negative part of this figure (18), reactivity is decreased due to the negative temperature feedback at $t=700(\mathrm{Sec}), \rho=\left(-4.3^{*} 10^{-3}\right)$.In the upper positive part, reactivity is increased due to the positive reactivity resulting of the control rods withdrawal at $t=20(\mathrm{Sec}), \rho=\left(+3.3^{*} 10^{-3}\right)$. 
In the second case (Eq. (24)): reactivity is decreased from upper part to below part. In the below negative part of this figure, reactivity is decreased due to the negative temperature feedback at $t=200$ (Sec), $\rho=\left(-6.50 * 10^{-3}\right)$. In the upper positive part, reactivity is increased due to the positive reactivity resulting from the control rods withdrawal at $t=20(\mathrm{Sec}), \rho=\left(+7.50^{*} 10^{-3}\right)$.

The results of figure (18) indicate that: in the two cases, the net reactivity decreases from positive to negative.

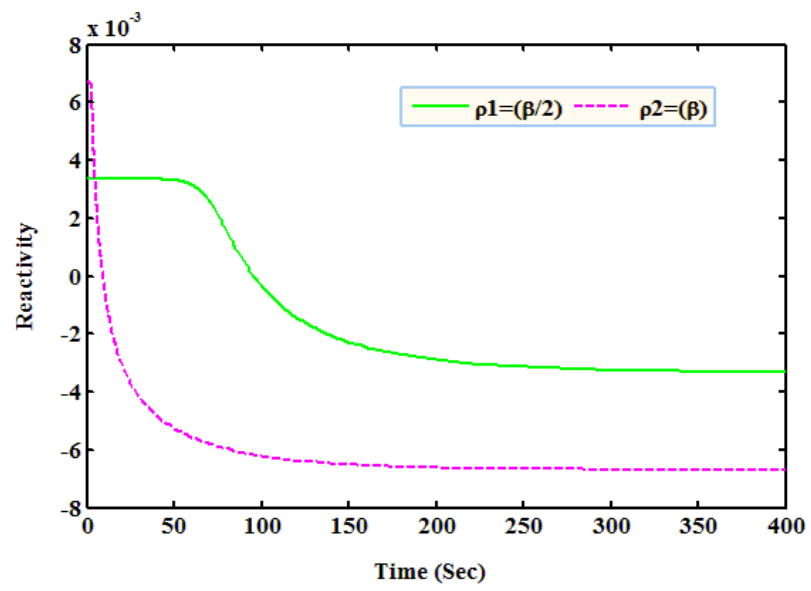

Figure 18 : Shows Reactivity Transients at Starup Condition for HTR-M Reactor.

\section{CONCLUSIONS}

Computer program is designed to solve the point reactor dynamics equations using the stiffness confinement method (SCM) and different input reactivity is applied (step, ramp and sinusoidal) the resultant powers are determined and illustrated. Good accuracy in comparison with references values is obtained. After applying the (SCM) as used in references [1, 15, 16 and 17] in our equations using different input small and large reactivities finding accurate and good results satisfactory agreement is found. The model is applied to the thermal reactor. There is a modular high temperature gas-cooled reactor design like HTR-M reactor [11]. The HTR-M reactor is fuelled by $235 \mathrm{U}$ as fissile nuclides. In the work of Van Dam [2] (used it for comparison purpose), the author obtained reactivity accident due to negative temperature feedback after loss of cooling to different reactors with different fissile material. Reactivity, initiated accident is considered to be due to linear temperature feedback and an adiabatic heating of the core after loss of cooling. In the present work, considering reactivity accident to be due to linear temperature feedback, an adiabatic heating of the core after loss of cooling with the positive reactivity due to control rods withdrawal. By analyzing accidents in a thermal reactor (HTR-M), and used the stiffness confinement method for solving the kinetics equations and addition part in reactivity equation due to control rods withdrawal. In the present work, obtaining reactivity induced accident due to control rods withdrawal with negative temperature feedback and the positive reactivity of the control rods withdrawal to overcome the occurrence of control rods withdrawal accident and prevent reactors from damage. The positive reactivity is used for two cases: $(\beta / 2, \beta)$ at full power and start-up conditions. One can also observe that for the HTR-M thermal reactor, at full power condition the power ratio increase by factor of 53.50 times the initial value at equilibrium temperature of $1,000(\mathrm{~K})$, when reactivity is increased by $\beta$, and, at start-up condition, the power ratio increases by a factor of 42.90 times the initial value at equilibrium temperature of 1,000 (K), when reactivity is increased by $\beta$. So at start-up condition the results of power, temperature, and reactivity figures are less than at full power condition and found accurate and good results compared with previous published works. 


\section{ACKNOWLEDGEMENTS}

One of the authors (H. M. S.) would like to give her appreciations to: Prof. Dr. Hesham Mansour, for his kind supervision and patience. He has been a great source of knowledge encouragement and guidance. Prof. Dr. Moustafa Aziz, for his supervision and continuous help, support and valuable guidance during this work, I am also grateful to my family for their support and love.

The authors would like also to thank all their friends in the Egyptian Nuclear Radiological Regulatory Authority.

\section{REFERENCES}

[1] Y. Chao, Al. Attard, A resolution to the stiffness problem of reactor kinetics, Nuclear Science and Engineering 90 (1985) 40-46.

[2] H. Van Dam, Dynamics of passive reactor shutdown, Prog. Nucl. Energy 30 (1996) 255.

[3] A. A. Nahla, E. M. E. Zayed,"Solution of the nonlinear point nuclear reactor kinetics equations", Prog. Nucl. Energy, P. (1-4), (2010).

[4] J.J. Duderstadt, L.J, L.J, L.J, L.J. Hamilton, Nuclear Reactor Analysis. John Wiley \& Sons, 1976, pp. 233-251.

[5] D. McMahon, A. Pierson, A Taylor series solution of the reactor point kinetics equations, arXiv: 1001.41002 (2010) 1-13.

[6] T.A. Porsching, The numerical solution of the reactor kinetics equations by difference analogs: A comparison of methods, WAPD-TM-564, U.S. National Bureau of Standards, U.S. Department of Commerce (1966) 1-44.

[7] B. Mitchell, Taylor series methods for the solution of the point reactor kinetic equations, Annals of Nuclear Energy 4 (1977) 169-176.

[8] B. Quintero-Leyva, CORE: A numerical algorithm to solve the point kinetics equations, Annals of Nuclear Energy 35 (2008) 2136-2138.

[9] M. Kinard, E.J. Allen, Efficient numerical solution of the point kinetics equations in nuclear reactor dynamics, Annals of Nuclear Energy 31 (2004) 1039-1051.

[10] D.L. Hetrick, Dynamics of Nuclear Reactors, University of Chicago Press, Chicago, 1971.

[11] K. Kugeler, R. Schulten, High Temperature Reactor Technology, Springer, Berlin, 1989, pp. $246-260$.

[12] Samuel, G., Alexander, S., 1994. Nuclear Reactor Engineering. Chapman \& Hall, Inc, PP. 296-299, ISBN 0-412-98521-7.

[13] Zhang, F.B., 2000. Operating Physics of Nuclear Reactor. Atomic Energy Press, Beijing, ISBN 75022-2187-5, pp. 231-236 (in Chinese).

[14] Cai, Z.S., Yu, L., Cai, Q., 2003. Neutron flux response to small reactivity with temperature feedback. Chinese Journal of Nuclear Science and Engineering. 23 (1), 58-60 (in Chinese).

[15] H. M. Saad, et al," Analysis of Reactivity Induced Accident for Control Rods Ejection with Loss of Cooling", Journal of Materials Science and Engineering B3 (2), P. (128-137), (2013).

[16] H. M. Saad, et al," Analysis of Reactivity - Initiated Accident for Control Rods Ejection ", Journal of Nuclear and Particle Physics 3 (4), P. (45-54), (2013).

[17] Hend Mohammed El Sayed Saad, Hesham Mohamed Mohamed Mansour , Moustafa Aziz Abdel Wahab, "Analysis of Reactivity Induced Accidents in Power Reactors [Paperback] ",LAP Lambert Academic Publishing GmbH \& Co., Saarbrucken, Germany.ISBN-13: 978-3639515558. (2013), Book at Amazon.com.

\section{Authors}

\section{1- Hend Mohammed El Sayed Saad}

Short Biography:

I am Assistant Lecturer in Egyptian Nuclear and Radiological Regulatory Authority. I have Master degree in reactivity analysis in power reactors. My knowledge is in nuclear engineering, nuclear reactor theory, nuclear reactor dynamics, nuclear reactor analysis and physics. Also, Codes knowledge with Computer code (MATLAB), and programming language (FORTRAN)

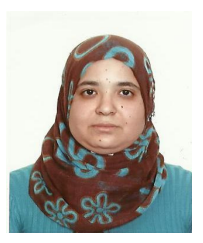

